\title{
The association between caffeine intake and forearm bone mineral density in postmenopausal women: The Oslo Health Study
}

\author{
Kristin Holvik $^{1}$ and Haakon E. Meyer ${ }^{1,2}$ \\ ${ }^{1}$ Division of Epidemiology, Norwegian Institute of Public Health, Oslo, Norway \\ 2 Institute for Nutrition Research, University of Oslo, Norway \\ Correspondence: Kristin Holvik, Norwegian Institute of Public Health, P.O.Box 4404 Nydalen, 0403 Oslo, Norway \\ E-mail: kristin.holvik@fhi.no
}

\begin{abstract}
Aim: To explore the relationship between caffeine intake and distal and ultradistal forearm bone mineral density (BMD) in postmenopausal women living in Oslo.

Methods: We used data from the osteoporosis supplementary project of the Oslo Health Study 20002001. Data from 695 women born in 1940-41 was included in the analyses. Information about diet and background variables was collected through a self-administered questionnaire. Estimates of caffeine intake were made from the reported consumption of coffee and caffeinated soft drinks, and estimates of calcium intake were made from the reported consumption of milk, yoghurt and cheese. Distal and ultradistal forearm BMD was measured by Single energy x-ray absorptiometry (SXA). Osteoporosis was defined as having a BMD of 2.5 standard deviations or more below average BMD in young women.

Results: Caffeine intake was significantly associated with ultradistal (coefficient $=-0.028, \mathrm{p}=0.016$ ) but not distal BMD (coefficient $=-0.016, \mathrm{p}=0.11$ ) after adjustment for a variety of potential confounders. The associations were attenuated after additional adjustment for postmenopausal hormone therapy (HT). Those who consumed a combination of high caffeine and low calcium had an odds ratio of 2.70 (95\% CI 1.12-6.51) of having osteoporosis in the ultradistal forearm compared to the low caffeine/high calcium consumers. This pattern was seen in current non-users of HT but not in current HT users.

Conclusion: Caffeine may have a weak negative influence on BMD which is more pronounced in the ultradistal than in the distal forearm. There may be a beneficial influence on BMD of a low caffeine intake combined with a high calcium intake.
\end{abstract}

\section{INTRODUCTION}

Fractures of the hip and forearm is a large health problem in the elderly. There is evidence that certain nutritional factors may exert a negative effect on bone through a negative calcium balance and among these are caffeine (1). It has been demonstrated that caffeine increases urinary excretion of calcium in at least three hours after intake, and that this effect is proportional to the dose of caffeine per lean body mass. The effect is likely to be attributed to reduced renal reabsorption. In contrast to other stimulating effects of caffeine, there is no apparent adaptation to caffeine induced hypercalciuria (2). Thus a long-term high caffeine intake may involve considerable calcium losses which, if not compensated for, could be suspected to increase the risk of reduced bone mineral density (BMD) through decalcification of the skeleton. It is well established that a low BMD is a strong marker for fracture risk (3). Caffeine may thus via an effect on BMD be a factor contributing to osteoporotic fractures. Some epidemiological studies have found a higher risk of fractures with a higher coffee or caffeine intake $(1,4-6)$, whereas others have found no relationship between a high coffee or caffeine intake and fracture risk in postmenopausal women (7-11). Some (12-15) but not all (16-21) have found an inverse relationship between coffee or caffeine intake and BMD or BMD change in postmenopausal women. It has been stated that if such a relationship exists it is likely to be most pronounced if dietary calcium is inadequate, and less harmful when dietary calcium is moderate or high $(22,23)$. Since fracture frequency in Oslo is among the highest in the world (24) and coffee consumption in Norway also is among the highest in the world (25), it is of interest to study the relation between coffee intake and BMD in this population. The relation between coffee intake and fracture risk in middle-aged Norwegians has previously been evaluated and found to be positive in women (1) but the relation between caffeine intake and BMD in Oslo citizens remains yet to be established. In connection with the Oslo Health Study we had the opportunity to study the relationship between dietary caffeine intake and distal and ultradistal forearm BMD in postmenopausal women born in 1940 and 1941 .

\section{MethodS}

The Oslo Health Study (HUBRO) was a cross-sectional population based multipurpose study conducted in 2000-2001 under the joint collaboration of the National Health Screening Service of Norway (now the Nor- 
wegian Institute of Public Health), the University of Oslo and the Municipality of Oslo. The overall attendance rate was $46 \%(n=18,770)$, varying from $36 \%$ in those 30 years old to $55 \%$ in those 59-60 years old. Approximately 2600 also participated in the osteoporosis supplementary project. Random samples of persons of both sexes born in 1925, 1940, 1955, 1960 and 1970 were invited. In addition, women born in 1941 who had participated in a health screening in 1981 were also invited. We included women born in 1940 and -41 (ages 59-60) for the present study. Six hundred and ninety-five women had valid data for BMD measurements. The numbers in the analyses may vary due to missing data. Distal and ultradistal forearm BMD was measured by Single energy x-ray absorptiometry (SXA). The bone densitometer (Osteometer, DTX 100) had previously been used in the Tromsø osteoporosis study, and the same protocol was used (26). A self-administered questionnaire developed for the Oslo Health Study (the HUBRO main questionnaire) provided information about dietary variables, physical activity, smoking, age at menopause and postmenopausal hormone therapy (HT). An additional registration form at the BMD measurement provided information about use of peroral corticosteroids and calcium supplements. A subset were also asked about decaffeinated coffee. As only $2 \%$ of the coffee drinkers in this subset reported habitual consumption of decaffeinated coffee, we have considered all coffee drinkers to be consuming caffeinated coffee. A clinical examination included anthropometric measures such as height and weight from which we calculated body mass index (BMI). As tea intake (in contrast to coffee or colas) has been shown to correlate positively with BMD in some studies $(9,27,28)$, we estimated caffeine intake from the reported consumption of coffee and caffeinated soft drinks. Caffeine content in beverages was based on figures from the International Food Information Council (29) and figures obtained from the Norwegian soft drink producing companies (Ringnes AS, Coca-Cola Drikker AS). An estimate of dietary calcium intake was made from the reported consumption of milk/yoghurt and cheese. The calcium content of these foods was based on figures from the Norwegian food composition table (30). We used standard cup and glass sizes (31). We did not include calcium supplements, as preliminary analyses suggested that supplement users had lower BMD and higher frequency of self-reported osteoporosis compared to non-supplement users (data not shown), and may thus be suspected to take supplements as a consequence of awareness of their low BMD or established osteoporosis. Data analyses were performed with the statistical software SPSS 11.0 for Windows. Distal BMD was normally distributed with a mean of $0.426 \mathrm{~g} / \mathrm{cm}^{2}$ (range 0.245-0.594). We also considered ultradistal BMD to be normally distributed, with a mean of 0.332 $\mathrm{g} / \mathrm{cm}^{2}$ (range $0.159-0.512 \mathrm{~g} / \mathrm{cm}^{2}$ ). One-way betweengroups ANOVA and linear regression analyses were performed to explore the relationship between caffeine intake and BMD. Additional regression analyses were performed with cups of coffee consumed daily as the caffeine indicator. Ultradistal BMD was adjusted for increased local BMD in those who had experienced a history of forearm fractures: $0.039 \mathrm{~g} / \mathrm{cm}^{2}$ in dominant arm and $0.038 \mathrm{~g} / \mathrm{cm}^{2}$ in non-dominant arm (32). Estimates of dietary calcium intake, age, years since menopause, BMI, light and heavy physical activity as well as current and former smoking were treated as confounding variables and controlled for in the statistical analyses, as they are established factors known to influence osteoporosis risk. An additional adjustment for current and former HT was included in an alternative multivariate regression model. Additional analyses were performed on Norwegian-born women only as ethnicity may be a confounder, and on those who did not report use of peroral corticosteroids, as corticosteroid use is associated with considerable bone loss. A BMD of 2.5 standard deviations or more below the average BMD in young women ( $\mathrm{t}$-score $\square 2.5$ ) implies osteoporosis according to the WHO definition (33). We calculated a t-score for the ultradistal forearm site, based on Norwegian data from the NOREPOS study. Logistic regression analysis was performed to explore a possible relationship between combined caffeine and calcium intake and osteoporosis according to the WHO definition. We divided intakes of both into halves (below and above median) and created thus four categories, making the combination of low caffeine and high calcium the indicator. The multivariate analysis was performed both with and without additional adjustment for current and former HT. Continuous logistic regression was performed to test for a trend through the categories of combined caffeine and calcium intake. For all statistical analyses the significance level was set to 0.05 .

\section{Results}

\section{Background characteristics}

Data from 695 women born in 1940 and -41 were available, including both Norwegian-born $(90 \%)$ and women with other native countries (10\%). Mean and median estimated caffeine intake were both $174 \mathrm{mg} /$ day, range $0-920 \mathrm{mg} /$ day $(\mathrm{n}=661)$. Estimates of calcium from milk and cheese ranged from 0 to $972 \mathrm{mg} /$ day (mean $309 \mathrm{mg} /$ day, median $297 \mathrm{mg} /$ day, n=559). There were substantially fewer HT users among those who had higher caffeine intakes (table 1). The proportion of current smokers was three times greater among high-caffeine consumers than low-caffeine consumers. Of the background variables, current HT use showed the strongest association with BMD.

\section{Distal BMD}

When dividing caffeine intake into tertiles of low (0$101 \mathrm{mg} /$ day), medium (116-188 mg/day) and high in- 
Table 1. Background characteristics of women according to having a caffeine intake from coffee and soft drinks below respectively above median of intake.

\begin{tabular}{|c|c|c|c|}
\hline & $\begin{array}{c}\text { Caffeine intake below } \\
\text { median }(\leq 174 \mathrm{mg} / \text { day })\end{array}$ & $\begin{array}{c}\text { Caffeine intake above } \\
\text { median }(>174 \mathrm{mg} / \text { day })\end{array}$ & $\mathrm{p}$ value $^{3}$ \\
\hline Estimates of calcium intake, $\mathrm{mg} /$ day $^{1}$ & 311 & 307 & 0.81 \\
\hline Calcium supplement users (\%) & 19 & 13 & 0.08 \\
\hline Current smokers $(\%)$ & 13 & 39 & 0.000 \\
\hline Inactive $^{2}(\%)$ & 22.4 & 21.7 & 0.90 \\
\hline $\operatorname{BMI}^{1}\left(\mathrm{~kg} / \mathrm{m}^{2}\right)$ & 26.1 & 25.7 & 0.31 \\
\hline Years since menopause $^{1}$ & 9.4 & 10.0 & 0.11 \\
\hline Current HT users (\%) & 51 & 38 & 0.002 \\
\hline Corticosteroid users (\%) & 2.9 & 2.4 & 0.89 \\
\hline
\end{tabular}

takes $(192-920 \mathrm{mg} /$ day), we observed decreasing distal BMD by increasing caffeine intake, with a difference of $0.015 \mathrm{~g} / \mathrm{cm}^{2}$ (p(post hoc test) $=0.02$ ) between lowest and highest tertile (table 2). Adjustment for age and current smoking produced similar results (not shown). Caffeine was significantly inversely associated with distal BMD in the univariate regression analysis (table 3). The magnitude of the association persisted in the multivariate model before adjustment for HT, but did not reach statistical significance, possibly due to loss of power. However, when including an adjustment for current and former HT use in the model, the regression coefficient was markedly reduced. The multivariate association was similar when excluding women not born in Norway and slightly attenuated when excluding users of peroral corticosteroids (data not shown). An association between cups of coffee and distal BMD approaching significance was observed $(\mathrm{n}=681$, coefficient $=-0.010, p=0.068$ per five cups). This was of similar magnitude but not significant when controlling for all confounders except HT use ( $\mathrm{n}=462$, coefficient $=-0.011, p=0.11$ for five cups), probably due to loss of power. However, the association was attenuated when also controlling for HT use in the model $(\mathrm{n}=433$, coefficient $=-0.008, \mathrm{p}=0.23$ for five cups $)$.

\section{Ultradistal BMD}

Ultradistal BMD decreased by increasing caffeine intake, with a difference of $0.020 \mathrm{~g} / \mathrm{cm}^{2}$ ( $\mathrm{p}$ (post hoc test $=0.004$ ) between lowest and highest tertile (table $2)$. The results were similar when controlling for age and current smoking (not shown). Caffeine was significantly inversely associated with ultradistal BMD in the univariate regression analysis (table 3). The association persisted in the multivariate model before adjustment for HT but was attenuated when entering current and former HT use in the model. The multivariate association was not substantially altered when excluding women not born in Norway or when excluding users of peroral corticosteroids (data not shown). We observed a statistically significant association between cups of daily coffee and ultradistal BMD ( $\mathrm{n}=677$, coefficient $=-0.015$ per five cups, $p=0.009$ ), which persisted in the multivariate model before adjustment for HT $(\mathrm{n}=460$, coefficient $=-0.020, \mathrm{p}=0.010)$. The association was still present although of borderline significance when also controlling for current and former HT use $(\mathrm{n}=432$, coefficient $=-0.015, \mathrm{p}=0.053)$.

\section{Impact of calcium intake}

Seventy-nine women (11.4\%) had osteoporosis according to the WHO definition, based on measurement in the ultradistal forearm. Those who had a combination of a high caffeine intake and a low calcium intake had a significantly increased OR of osteoporosis compared to those who had a combination of a low caffeine intake and a high calcium intake (table 4). This association persisted in the multivariate model before adjustment for HT, but was attenuated after additional adjustment for current and former HT use. When entering the categories of combined caffeine and calcium intake as a continuous variable, OR for osteoporosis per increasing category was $1.37(\mathrm{p}=0.024, \mathrm{n}=461)$ in the multivariate model without adjustment for HT. The same relationship was present in those who did not report current HT use $(\mathrm{OR}=1.38$ per increasing category, $\mathrm{p}=0.042, \mathrm{n}=249$ ), but could not be observed in current HT users $(n=184)$, possibly due to low power as there were few osteoporosis cases in this group. A similar although weaker pattern was observed when basing the model on distal instead of ultradistal BMD (data not shown).

Table 2. Mean unadjusted distal $(\mathrm{n}=661)$ and ultradistal BMD $(n=657)$ in tertiles of caffeine intake from coffee and soft drinks in the sample of postmenopausal women.

\begin{tabular}{lcccc}
\hline & & \multicolumn{3}{c}{ Tertiles of caffeine intake } \\
\cline { 3 - 5 } & Total (SD) & Low & Medium & High \\
\hline Distal BMD $\left(\mathrm{g} / \mathrm{cm}^{2}\right)$ & $0.425(0.056)$ & 0.434 & 0.425 & 0.419 \\
Ultradistal BMD $\left(\mathrm{g} / \mathrm{cm}^{2}\right)$ & $0.332(0.061)$ & 0.343 & 0.332 & 0.323 \\
\hline
\end{tabular}


Table 3. Univariate and multivariate linear regressions of caffeine intake versus distal and ultradistal BMD $\left(\mathrm{g} / \mathrm{cm}^{2}\right)$.

\begin{tabular}{|c|c|c|}
\hline Daily caffeine intake, per $500 \mathrm{mg}$ & Coefficient & $\mathrm{p}$ value \\
\hline \multicolumn{3}{|l|}{ Distal BMD } \\
\hline Univariate model, $\mathrm{n}=661$ & -0.017 & 0.035 \\
\hline $\begin{array}{l}\text { Multivariate model } \mathrm{I}, \mathrm{n}=463 \text { (Adjusted for age, estimated calcium intake, BMI, light and heavy physical activity, } \\
\text { years since menopause and current and former smoking) }\end{array}$ & -0.016 & 0.11 \\
\hline Multivariate model II, n=434 (Additional adjustment for current and former postmenopausal hormone therapy) & -0.011 & 0.29 \\
\hline \multicolumn{3}{|l|}{ Ultradistal BMD } \\
\hline Univariate model, $\mathrm{n}=657$ & -0.023 & 0.008 \\
\hline $\begin{array}{l}\text { Multivariate model I, } \mathrm{n}=461 \text { (Adjusted for age, estimated calcium intake, BMI, light and heavy physical activity, } \\
\text { years since menopause and current and former smoking) }\end{array}$ & -0.028 & 0.016 \\
\hline Multivariate model II, n=433 (Additional adjustment for current and former postmenopausal hormone therapy) & -0.019 & 0.10 \\
\hline
\end{tabular}

Table 4. Rates and odds ratios with $95 \%$ confidence intervals for osteoporosis (ultradistal BMD $\leq 2.5$ SD below young adult mean) according to categories of caffeine and calcium intake.

\begin{tabular}{|c|c|c|c|c|}
\hline \multirow[b]{2}{*}{ Category } & Cases $(\%)$ of osteoporosis & $\mathrm{OR}^{1}(95 \% \mathrm{CI})$ & \multirow{2}{*}{$\begin{array}{c}\mathrm{OR}^{2}(95 \% \mathrm{CI}) \\
\mathrm{n}=461\end{array}$} & \multirow{2}{*}{$\begin{array}{c}\mathrm{OR}^{3}(95 \% \mathrm{CI}) \\
\mathrm{n}=433\end{array}$} \\
\hline & \multicolumn{2}{|l|}{$\mathrm{n}=546$} & & \\
\hline Low caffeine/high calcium & $12(8.5)$ & 1.00 (ref.) & 1.00 (ref.) & 1.00 (ref.) \\
\hline High caffeine/high calcium & $10(11.4)$ & $1.38(0.57-3.34)$ & $1.47(0.55-3.88)$ & $1.39(0.51-3.76)$ \\
\hline Low caffeine/low calcium & $25(13.1)$ & $1.62(0.78-3.35)$ & $1.79(0.80-4.00)$ & $1.81(0.77-4.24)$ \\
\hline High caffeine/low calcium & $23(18.3)$ & $2.40(1.14-5.05)$ & $2.70(1.12-6.51)$ & $2.03(0.82-5.05)$ \\
\hline
\end{tabular}

${ }^{1}$ Unadjusted

${ }^{2}$ Adjusted for age, BMI, light and heavy physical activity, years since menopause, current and former smoking.

${ }^{3}$ Additional adjustment for current and former postmenopausal hormone therapy.

\section{DISCUSSION}

We found a negative association between caffeine intake and forearm BMD, which was significant at the ultradistal but not the distal site in the multivariate model. After additional adjustment for HT there were no significant associations between caffeine and BMD. We also found an increased odds ratio for osteoporosis in those who had a combination of a high caffeine and a low calcium intake compared to those who had a low caffeine and a high calcium intake. This relationship was only present in current non-users of HT.

\section{Methods}

We investigated both the distal and the ultradistal forearm, as they have different proportions of trabecular and cortical bone and may thus be influenced differently by dietary and lifestyle factors. The regression analysis was performed with both milligrams of daily caffeine and with number of coffee cups consumed daily as caffeine indicator. The advantage of using estimated caffeine intake was that it allowed us to differentiate between the varying caffeine content in coffee due to different preparation methods, and that it could be expected to be a more accurate indicator of caffeine intake as it included the contribution from other caffeine sources as well as coffee. However, the power of the analysis was greatly reduced due to missing data when constructing a complex variable on the basis of several questions. Counting cups of coffee may provide a simple and practical description of caffeine effect. Firstly, it is easier interpretable; secondly, other caffeinated beverages may not share coffee's effect on bone, as has been demonstrated with respect to tea $(9,27,28)$. Our analyses indicated that applying caffeine or coffee produced similar results. We did not include caffeine from tea in the analyses, as it was expected to not contribute to the possible negative influence of coffee and soft drinks on BMD. A positive influence of tea drinking on BMD has previously been suggested $(9,27,28)$. Tea may have a direct protective biologic effect on bone tissue, which may be due to certain constituents of tea, such as various flavonoids, fluoride or polyphenols and tannins (28). Another possible explanation is that tea drinking may, in contrast to coffee and cola drinking, simply be confounded by other health-promotional behaviour. This would make tea an indicator of general health-promotional behaviour whereas coffee may be an indicator of unfavourable health behaviour or variables connected to health behaviour (34). The estimated calcium intake from milk/yoghurt and cheese was low and cannot be considered to be an estimate of total daily calcium intake. However, it is likely to be sufficient to rank the subjects according to their calcium intake, as milk and cheese constitute about $70 \%$ of total calcium intake in the average Norwegian diet (35). We have evaluated the calcium and caffeine data by comparing them with another method in a subset of the participants in the osteoporosis supplementary 
project, where we found good agreement for the calcium data and very good agreement for the caffeine data (36).

\section{Background variables}

Smoking was strongly related to caffeine intake, and smoking is known to be an important confounder for coffee. Current HT use was the variable that showed the strongest association with BMD. It has been demonstrated in randomised controlled trials that HT has a strong positive effect on BMD (37).

\section{BMD}

The observed decreasing BMD by increasing caffeine intake may be a result of confounding. However, the magnitude of the regression coefficients was not substantially altered after adjustment for factors that are known to influence BMD. After additional adjustment for current and former HT, however, the association was attenuated and not significant. The association between caffeine and BMD was stronger in the ultradistal than in the distal area, contrary to the findings in the Norwegian Nord-Trøndelag Health Survey (21). There is a larger proportion of trabecular bone in the ultradistal (50-70\%) compared to the distal forearm (10-20\%), and a stronger association with caffeine in the more metabolically active trabecular bone seems plausible.

\section{Impact of calcium}

An association between caffeine and BMD may depend on the magnitude of the calcium intake. We observed increased odds ratios for osteporosis in the high caffeine/low calcium consumers compared to the low caffeine/high calcium consumers, also after adjustment for a variety of confounders. The results support the notion that high caffeine intakes combined with low calcium intakes may influence BMD negatively $(22,23)$. The relationship was attenuated after adjustment for current and former HT. However, in non-current users of HT a trend of increasing odds ratios for increasing categories of combined caffeine and calcium intake was present. HT has a well-documented strong positive effect on BMD (37). There is evidence that estrogen stimulates intestinal calcium absorption, either directly or via vitamin D (38). It is thus possible that factors that influence calcium balance (such as caffeine) may act differently in those who use HT than in those who do not. However, the power to explore the association between caffeine and BMD in current
HT users was low, due to very few cases of osteoporosis in this group.

\section{Limitations of the study}

As this is a cross-sectional study where all information from each subject was obtained at one specific point in time, we are not able to distinguish what behaviour has led to which consequences. Awareness of disease or health condition may have influenced behaviour such as diet. Report of a high calcium intake at this point in time would not necessarily reflect a lifetime high calcium intake. For instance, even though a significant negative relationship between calcium supplement use and BMD was observed, no conclusions can be drawn on this basis as the subjects may use calcium supplements due to awareness of their low BMD.

\section{CONCLUSION}

We found a moderate negative association between caffeine intake and distal and ultradistal BMD in women 59-60 years of age, which was still apparent after adjustment for potential confounders, but was attenuated after controlling for HT use. The association was stronger in the ultradistal than in the distal forearm, suggesting that the ultradistal forearm is more susceptible in the early postmenopausal years. We also found an increased odds ratio of osteoporosis in the high caffeine/low calcium consumers compared to the low caffeine/high calcium consumers, suggesting a beneficial influence on BMD of a low caffeine intake combined with a high calcium intake, also when controlling for potential confounders. This pattern could only be observed in those who did not report current HT use. Our results suggest a possible beneficial influence on BMD of consuming lower amounts of coffee combined with higher amounts of calcium. Our findings are in agreement with previous findings from similar studies conducted in some populations, whereas other investigators have not come to the same results. No consensus has yet been established of the importance of caffeine for BMD and fracture risk.

\section{ACKNOWLEDGEMENT}

The data collection was conducted as part of the Oslo Health Study 2000-2001 in collaboration with the National Health Screening Service of Norway - now the Norwegian Institute of Public Health. This paper is based on Kristin Holvik's cand. scient. thesis in clinical nutrition at the Institute for Nutrition Research, University of Oslo, Norway, 2003.

\section{REFERENCES}

1. Meyer HE, Pedersen JI, Løken EB, Tverdal A. Dietary factors and the incidence of hip fracture in middleaged Norwegians. A prospective study. Am J Epidemiol 1997; 145 (2): 117-123.

2. Massey LK, Whiting SJ. Caffeine, urinary calcium, calcium metabolism and bone. J Nutr 1993; 123 (9): 1611-1614. 
3. Marshall D, Johnell O, Wedel H. Meta-analysis of how well measures of bone mineral density predict occurrence of osteoporotic fractures. BMJ 1996; 312 (7041): 1254-1259.

4. Cummings SR, Nevitt MC, Browner WS, Stone K, Fox KM, Ensrud KE, et al. Risk factors for hip fracture in white women. Study of Osteoporotic Fractures Research Group. N Engl J Med 1995; 332 (12): 767-773.

5. Hernandez-Avila M, Colditz GA, Stampfer MJ, Rosner B, Speizer FE, Willett WC. Caffeine, moderate alcohol intake, and risk of fractures of the hip and forearm in middle-aged women. Am J Clin Nutr 1991; 54 (1): $157-163$.

6. Hansen SA, Folsom AR, Kushi LH, Sellers TA. Association of fractures with caffeine and alcohol in postmenopausal women: the Iowa Women's Health Study. Public Health Nutr 2000; 3 (3): 253-261.

7. Kreiger N, Gross A, Hunter G. Dietary factors and fracture in postmenopausal women: a case-control study. Int J Epidemiol 1992; 21 (5): 953-958.

8. Nieves JW, Grisso JA, Kelsey JL. A case-control study of hip fracture: evaluation of selected dietary variables and teenage physical activity. Osteoporos Int 1992; 2 (3): 122-127.

9. Johnell O, Gullberg B, Kanis JA, Allander E, Elffors L, Dequeker J, et al. Risk factors for hip fracture in European women: the MEDOS Study. Mediterranean Osteoporosis Study. J Bone Miner Res 1995; 10 (11): $1802-1815$.

10. Tavani A, Negri E, La Vecchia C. Coffee intake and risk of hip fracture in women in northern Italy. Prev Med 1995; 24 (4): 396-400.

11. Huopio J, Kroger H, Honkanen R, Saarikoski S, Alhava E. Risk factors for perimenopausal fractures: a prospective study. Osteoporos Int 2000; 11 (3): 219-227.

12. Bauer DC, Browner WS, Cauley JA, Orwoll ES, Scott JC, Black DM, et al. Factors associated with appendicular bone mass in older women. The Study of Osteoporotic Fractures Research Group. Ann Intern Med 1993; 118 (9): 657-665.

13. Cooper C, Atkinson EJ, Wahner HW, O'Fallon WM, Riggs BL, Judd HL, et al. Is caffeine consumption a risk factor for osteoporosis? J Bone Miner Res 1992; 7 (4): 465-471.

14. Rapuri PB, Gallagher JC, Kinyamu HK, Ryschon KL. Caffeine intake increases the rate of bone loss in elderly women and interacts with vitamin D receptor genotypes. Am J Clin Nutr 2001; 74 (5): 694-700.

15. Ilich JZ, Brownbill RA, Tamborini L, Crncevic-Orlic Z. To drink or not to drink: how are alcohol, caffeine and past smoking related to bone mineral density in elderly women? J Am Coll Nutr 2002; 21 (6): 536-544.

16. Lloyd T, Rollings N, Eggli DF, Kieselhorst K, Chinchilli VM. Dietary caffeine intake and bone status of postmenopausal women. Am J Clin Nutr 1997; 65 (6): 1826-1830.

17. Grainge MJ, Coupland CA, Cliffe SJ, Chilvers CE, Hosking DJ. Cigarette smoking, alcohol and caffeine consumption, and bone mineral density in postmenopausal women. The Nottingham EPIC Study Group. Osteoporos Int 1998; 8 (4): 355-363.

18. Hansen MA, Overgaard K, Riis BJ, Christiansen C. Potential risk factors for development of postmenopausal osteoporosis - examined over a 12-year period. Osteoporos Int 1991; 1 (2): 95-102.

19. Reid IR, Ames RW, Evans MC, Sharpe SJ, Gamble GD. Determinants of the rate of bone loss in normal postmenopausal women. J Clin Endocrinol Metab 1994; 79 (4): 950-954.

20. Lloyd T, Johnson-Rollings N, Eggli DF, Kieselhorst K, Mauger EA, Cusatis DC. Bone status among postmenopausal women with different habitual caffeine intakes: a longitudinal investigation. $J$ Am Coll Nutr 2000; 19 (2): 256-261.

21. Forsmo S, Schei B, Langhammer A, Forsen L. How do reproductive and lifestyle factors influence bone density in distal and ultradistal radius of early postmenopausal women? The Nord-Trøndelag Health Survey, Norway. Osteoporos Int 2001; 12 (3): 222-229.

22. Barrett-Connor E, Chang JC, Edelstein SL. Coffee-associated osteoporosis offset by daily milk consumption. The Rancho Bernardo Study. JAMA 1994; 271 (4): 280-283.

23. Harris SS, Dawson-Hughes B. Caffeine and bone loss in healthy postmenopausal women. Am J Clin Nutr 1994; 60 (4): 573-578.

24. Falch JA, Meyer HE. Osteoporose og brudd i Norge. Forekomst og risikofaktorer. Tidsskr Nor Laegeforen 1998; 118 (4): 568-572.

25. International Coffee Council. Coffee market situation coffee year 2001/02. Economic Report. International Coffee Organization. 18-9-2002.

26. Berntsen GK, Tollan A, Magnus JH, Søgaard AJ, Ringberg T, Fønnebø V. The Tromsø Study: Artifacts in forearm bone densitometry - prevalence and effect. Osteoporos Int 1999; 10 (5): 425-432.

27. Hegarty VM, May HM, Khaw KT. Tea drinking and bone mineral density in older women. Am J Clin Nutr 2000; 71 (4): 1003-1007.

28. Wu CH, Yang YC, Yao WJ, Lu FH, Wu JS, Chang CJ. Epidemiological evidence of increased bone mineral density in habitual tea drinkers. Arch Intern Med 2002; 162 (9): 1001-1006. 
29. IFIC. Caffeine \& Health: Clarifying the controversies. IFIC Review 7/98. International Food Information Council Foundation. Washington DC. 1998: 1-8.

30. Rimestad AH, Statens Ernæringsråd, Statens Næringsmiddeltilsyn. Matvaretabellen 1995. Oslo: Universitetsforlaget, 1995.

31. Blaker B, Aarsland M. Mål og vekt for matvarer. 2nd edition. Oslo: Landsforeningen for Kosthold og Helse, 1995.

32. Berntsen GK, Fønnebø V, Tollan A, Søgaard AJ, Magnus JH. Forearm bone mineral density by age in 7,620 men and women: The Tromsø study, a population-based study. Am J Epidemiol 2001; 153 (5): 465-473.

33. WHO. Assessment of fracture risk and its application to screening for postmenopausal osteoporosis. Report of a WHO Study Group. World Health Organ Tech Rep Ser 1994; 843: 1-129.

34. Schwarz B, Bischof HP, Kunze M. Coffee, tea, and lifestyle. Prev Med 1994; 23 (3): 377-384.

35. Johansson L, Solvoll K. Statens råd for ernæring og fysisk aktivitet. Norkost 1997. Landsomfattenede kostholdsundersøkelse blant menn og kvinner i alderen 16-79 år. Rapport nr 2, 1999. Oslo: Statens råd for ernæring og fysisk aktivitet, 1999.

36. Holvik K. What impact does caffeine intake have on bone mineral density? Supplementary project of the Oslo Health Study 2000. Thesis for the degree cand. scient. in clinical nutrition. Institute for Nutrition Research, Faculty of Medicine, University of Oslo, Norway, 2003.

37. Dören M, Nilsson JÅ, Johnell O. Effects of specific post-menopausal hormone therapies on bone mineral density in post-menopausal women: a meta-analysis. Hum Reprod 2003; 18 (8): 1737-1746.

38. Ten Bolscher M, Netelenbos JC, Barto R, Van Buuren LM, Van der Vijgh WJ. Estrogen regulation of intestinal calcium absorption in the intact and ovariectomized adult rat. J Bone Miner Res 1999; 14 (7): 1197-1202. 